\title{
Sacrospinous ligament fixation for prevention and treatment of vaginal vault prolapse: a retrospective study of 45 cases
}

\author{
Ramesh Kumar RK, Leena Kamat*, Shilpa T., Shruthi Andola
}

Department of Obstetrics and Gynaecology, SDM College of Medical Sciences and Hospital, Manjushree Nagar, Sattur, Dharwad - 580009, India

Received: 14 September 2016

Accepted: 08 October 2016

*Correspondence:

Dr. Leena Kamat,

E-mail: kamatleena082@gmail.com

Copyright: () the author(s), publisher and licensee Medip Academy. This is an open-access article distributed under the terms of the Creative Commons Attribution Non-Commercial License, which permits unrestricted non-commercial use, distribution, and reproduction in any medium, provided the original work is properly cited.

\section{ABSTRACT}

Background: To assess intraoperative and postoperative complications and to evaluate recurrence of vault prolapse in women who have undergone unilateral (left) Sacrospinous ligament fixation.

Methods: Between January 2007 and January 2015, 45 women (mean age 56.5 years, range 35 to 78 years) underwent vaginal unilateral (left) Sacrospinous ligament fixation at Shree Dharmasthala Manjunatheshwara (SDM) College of Medical Sciences, Dharwad, India. 15 patients had prior hysterectomy. Concomitant hysterectomy and Sacrospinous ligament fixation was performed in 30 patients. Sacrospinous ligament fixation was combined with additional procedures like Trans-Obturator tape (TOT) insertion in 2 (4.6\%) patients.

Results: All patients were analyzed for intraoperative and postoperative complications. 1 patient had Urinary tract infection $(n=1,2.2 \%), 1$ patient had haemorrhage requiring blood transfusion $(n=1,2.2 \%)$. The mean follow up was for 15 months (range 6 months to 24 months). 1 patient (2.2\%) had asymptomatic recurrent cystocele and 1 patient $(2.2 \%)$ had dyspareunia. No recurrence of vault prolapse was noted.

Conclusions: Sacrospinous ligament fixation is a simple, effective and safe procedure for treatment and prevention of vault prolapse with least complications and recurrence rates.

Keywords: Recurrence, SSLF, Vault prolapse

\section{INTRODUCTION}

Vaginal vault prolapse has been defined by the International Continence Society as descent of the vaginal cuff below a point that is $2 \mathrm{~cm}$ less than the total vaginal length above the plane of the hymen. ${ }^{1}$

Vaginal vault prolapse has been reported to follow $11.6 \%$ of hysterectomies performed for prolapse and $1.8 \%$ for other benign diseases. ${ }^{2}$ A large study from Austria estimated the frequency of vault prolapse requiring surgical repair to be between $6 \%$ and $8 \% .^{3}$ The cumulative risk for vault prolapse rises from $1 \%$ three years after a hysterectomy to 5\% 15 years after hysterectomy. Also the risk of prolapse following hysterectomy is 5.5 times in women whose initial hysterectomy was for genital prolapse as opposed to other reasons. ${ }^{4,5}$ Vault prolapse following hysterectomy is more likely if there was pre-existing pelvic floor defect or prolapse.Different procedures have been described for treatment as well as for prevention of vault prolapse. Zweifel described a vaginal reconstructive surgery by connecting vaginal vault to the Sacrotuberous ligament. Sederl described the idea of fixing the vaginal vault to the Sacrospinous ligament. ${ }^{6}$ Richter popularised the sacrospinous ligament fixation procedure. $^{7}$ The abdominal procedure includes sacral colpopexy. A clear and thorough understanding of the supporting mechanisms for the uterus and the vagina is important in order to make the right choice of the corrective procedure and also to minimise the risk of post hysterectomy occurrence of vault prolapse. 
In this study we present our data of intra and postoperative complications and recurrence.

\section{Objectives}

1. To analyze intra- operative and post-operative complications of Sacrospinous ligament fixation (SSLF).

2. To assess long term complications of SSLF.

3. To analyze recurrence following SSLF.

\section{METHODS}

Between January 2007 and January 2015, 45 patients with vaginal vault prolapse were selected for Sacrospinous ligament fixation at Shri Dharmasthala Manjunatheshwara College of Medical Sciences And Hospital, Dharwad. Prior to surgery all patients underwent clinical examination and Pelvic Organ Prolapse- Quantification (POP-Q) staging and a clinical stress test with an optimally filled bladder after repositioning the vaginal vault to detect masked stress urinary incontinence. In patients with demonstrable genuine stress incontinence additional anti incontinence surgery was performed. Women with POP-Q stage III and IV and those with vault prolapse after hysterectomy were included. Written and informed consent was taken in all patients. Approval from institute's ethical committee clearance was taken.

\section{Operative procedure}

Patients were operated under spinal anaesthesia in lithotomy position. Initially vaginal hysterectomy was performed in case of intact uterus. And then repair of anterior wall defects. Posterior vaginal incision made and extended up to the apex, enterocele sac identified and mobilized off the posterior vaginal wall up to its neck; the sac is opened and peritoneum excised. The defect is closed with purse string sutures. The pararectal space was dissected on left side and sacrospinous ligament was identified. A retractor (Breisky Navratil) was used to displace the rectum medially. Then under direct vision with long handled needle holder nonabsorbable suture material polypropylene 1 is passed through the sacrospinous ligament two fingers medial to the ischial spine. The second suture of delayed absorbable polyglactin 910 number 1 is passed through the ligament $1 \mathrm{~cm}$ medial to the first one. Suture site is confirmed for haemostasis. Then needle end of the nonabsorbable suture is passed through the full thickness of the fibro muscular layer of the under surface of the vaginaon the medial side excluding the epithelium and then tied by a half hitch, the other end of the suture is passed through the full thickness of the fibro muscular layer of the under surface of the vaginaon lateral side excluding the epithelium and a pulley stitch is created. The ends of the absorbable sutures are placed through the full thickness of the vagina on both sides. The upper portion of the vaginal wall is closed with number 1 polyglactin before tying the colpopexy sutures. Then colpopexy sutures were tied first the pulley stitch and then the reinforcing absorbable stitch. This is followed by posterior colporrhaphy and perineorrhaphy. Vaginal packing done with povidone iodine soaked gauze.

All patients were available for follow up post operatively both immediate and long term (range 6 months to 32 months).Evaluations included immediate complications like haemorrhage, urinary infections, febrile morbidity and gluteal pain. For long term follow up symptoms of recurrence of mass per vagina and physical examination for assessment of cystocele, rectocele, enterocele and recurrence of vault prolapse and for stress incontinence were carried out.

\section{RESULTS}

Table 1: Procedures combined with SSLF.

\begin{tabular}{|l|l|}
\hline Procedure & No. of patients \\
\hline Correction of enterocele & 45 \\
\hline Anterior colporrhaphy & 45 \\
\hline Vaginal hysterectomy & 30 \\
\hline $\begin{array}{l}\text { Reconstruction of urogenital } \\
\text { diaphragm }\end{array}$ & 45 \\
\hline Posterior colpo-perineorrhaphy & 45 \\
\hline TOT insertion & 2 \\
\hline
\end{tabular}

Table 2: Complications.

\begin{tabular}{|lll|}
\hline Complications & No. of patients & $\%$ of cases \\
\hline Urinary tract infection & 1 & $2.2 \%$ \\
\hline Voiding dysfunction & 0 & 0 \\
\hline Dyspareunia & 1 & $2.2 \%$ \\
\hline Recurrent cystocele & 1 & $2.2 \%$ \\
\hline $\begin{array}{l}\text { Hemorrhage requiring } \\
\text { blood transfusion }\end{array}$ & 1 & $2.2 \%$ \\
\hline $\begin{array}{l}\text { Recurrent vault } \\
\text { prolapse }\end{array}$ & 0 & 0 \\
\hline \begin{tabular}{l} 
Sciatic neuralgia \\
\hline
\end{tabular} & 0 & 0 \\
\hline
\end{tabular}

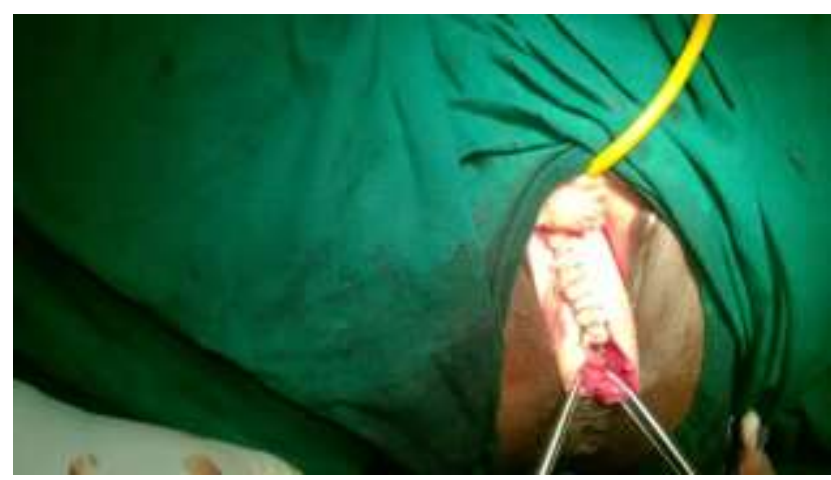

Figure 1: Intra-operative finding showing vaginal apex outside the level of introitus.

The patients age at the time of operation ranged from 35 to 78 years (mean age- 56.5 years). All 45patients underwent vaginal unilateral (left) Sacrospinous ligament 
fixation. 15 patients had prior hysterectomy. Concomitant hysterectomy and Sacrospinous ligament fixation was performed in 30 patients. Sacrospinous ligament fixation was combined with additional procedure TOT insertion in $2(4.4 \%)$ patients. Average duration of the surgery was 1 hour 25 minutes to 3 hours 40 minutes (mean 2 hours and 50 minutes).

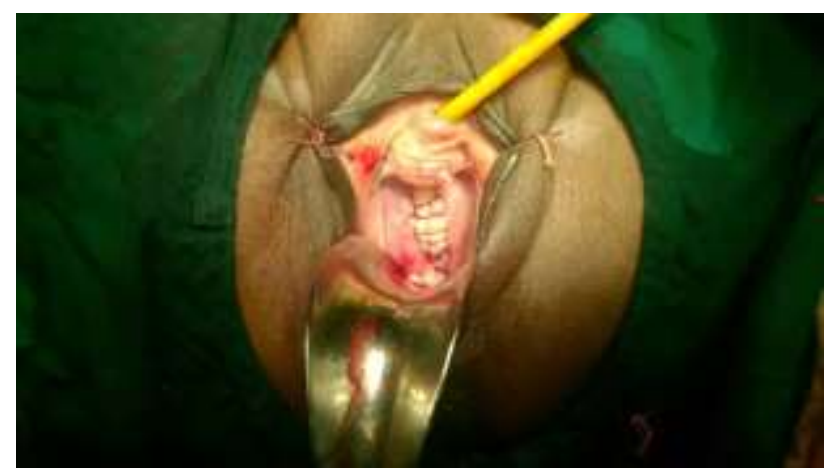

Figure 2: Post-operative image showing vaginal vault after SSL fixation.

Urinary tract infection occurred in one patient and responded to oral antibiotic treatment. One patient required blood transfusion. All patients recovered postoperatively without any complications.

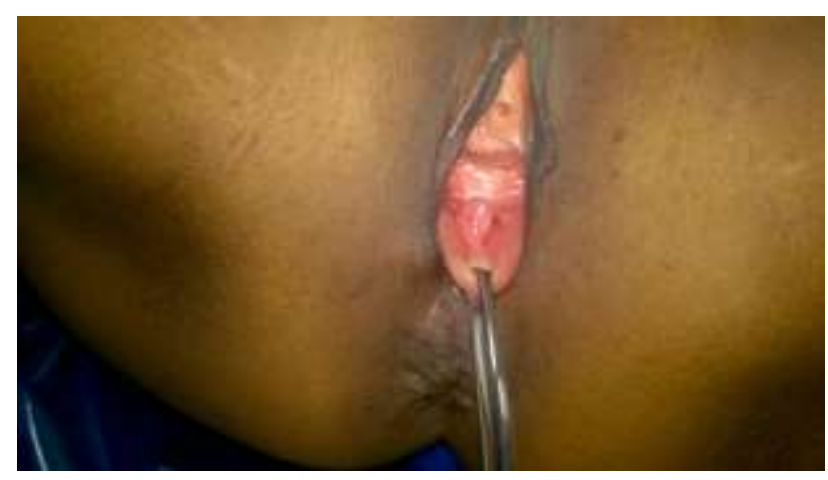

Figure 3: Vault prolapse (type 2).

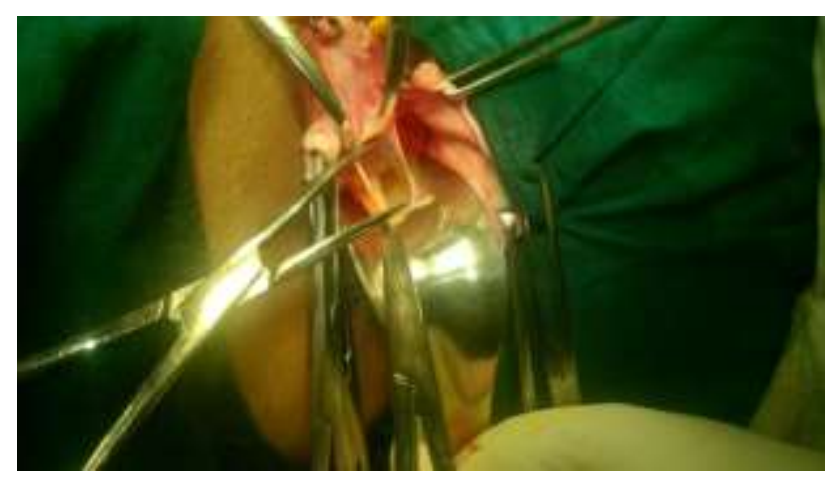

Figure 4: Enterocele sac opened.

All 45 patients were treated successfully without any symptom of recurrent vault prolapse on follow up. Recurrence rate of cystocele was $2.2 \%$ which was asymptomatic. Dyspareunia was reported in $1(2.2 \%)$ patients. All women were satisfied with surgical result.

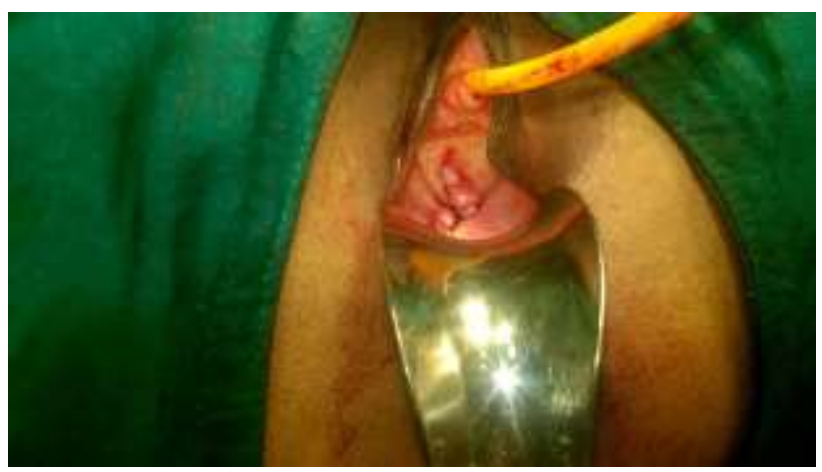

Figure 5: Vaginal vault after SSL fixation.

\section{DISCUSSION}

Vaginal vault prolapse is often a consequence of previous hysterectomy, either as a result of failure to identify and correct enterocele or due to co-existing pelvic floor defect at the time of primary surgery. Other causes are congenital deficiency in the collagen vascular system, damage of pelvic floor during child birth process, or due to postmenopausal asthenia due to oestrogen deficiency. ${ }^{8}$

Genital prolapse and vaginal vault prolapse following hysterectomy is one of the major concerns in perimenopausal and postmenopausal women and affect around $13 \%$ of women. This requires a simple, cost effective and safe operative procedure for prevention as well as for treatment. SSLF is simple, cost effective and safe operative technique with minimal morbidity and less long term recurrence risks.

Different staging systems have been proposed for prolapse. The commonly used system is POP-Q system. The Sacrospinous ligament fixation restores Level 1 vaginal support. ${ }^{9}$ Pelvic floor dysfunction affects $11 \%$ of women in their life time. ${ }^{10}$ Recurrence of prolapse occurs in $25 \%$ patients. The need for repeat surgery is $17 \% .^{11}$

The rates of recurrence were different in different studies. According to study done by Beer and Kuhn the failure rate was $3-37 \% .^{12}$ Failure rates were higher in anterior compartment defects and lowest in posterior and apical defects.

In our present study only one woman had recurrent cystocele but it was asymptomatic. The relief of mass per vagina symptom was noted in $100 \%$ women. There were no major intra-operative or post-operative complications. Only one patient had primary haemorrhage that needed blood transfusion. One patient had urinary tract infection and was treated with oral antibiotics. 
The draw backs of abdominal procedure includes need to enter the peritoneal cavity and higher intra operative and post-operative morbidity, longer hospital stay.

The three techniques of SSLF for passing the needle through SSL are 1. Direct visualisation 2. Deschamps ligature carrier by palpation and 3. Miya hook ligature carrier by palpation. According to Pollak et al the intra as well as post-operative complication were less with direct visualisation technique $(2 \%)$ when compared to Dischamps clamp. ${ }^{13}$

According to RCOG/BSUG joint guideline 1stJuly 2015, SSLF should be considered at the time of vaginal hysterectomy when the vault descends to the introitus during closure. ${ }^{14}$ SSLF is associated with earlier recovery compared to abdominal sacrocolpopexy. Concomitant mid urethral sling surgery for SUI may be considered during SSLF.

Use of mesh for pelvic defects includes risk of mesh related side effects like erosion, migration, infection and cost with no additional benefits. ${ }^{15}$ After conducting a systematic review FDA concluded that trans-vaginal pelvic organ prolapse repair with surgical mesh does not improve symptomatic results or quality of life over traditional repair procedures that do not use mesh. ${ }^{15}$ Though serious complications are rare with mesh, they are often difficult to treat and result in permanent disability. Removal of the mesh is also difficult and complex procedure.

\section{CONCLUSION}

Vaginal unilateral (left) Sacrospinous ligament fixation is a simple, safe and cost effective procedure and can be performed along with vaginal hysterectomy and for treatment of vault prolapse. As compared to abdominal or mesh procedures SSLF is cheaper and has less complications and has comparable success rates.

Funding: No funding sources

Conflict of interest: None declared

Ethical approval: The study was approved by the Institutional Ethics Committee

\section{REFERENCES}

1. Abrams P, Cardozo L, Fall M. The Standardization of Terminology of Lower Urinary Tract Function: Report from the Standardization Sub-committee of the International Continence Society. Neurourol Urodyn. 2002;21(2):167-78.
2. Marchionni M, Bracco GL, Checcucci V, Carabaneanu A, Coccia EM, Mecacci F. True incidence of vaginal vault prolapse. Thirteen years of experience. J Reprod Med. 1999;44(8):679-84.

3. Aigmueller T, Dungl A, Hinterholzer S, Geiss I, Riss P. An estimation of the frequency of surgery for post hysterectomy vault prolapse. Int Urogynecol J. 2010;21(3):299-302.

4. Flynn BJ, Webster GD. Surgical management of the apical vaginal defect. Curr Opin Urol. 2002;12(4):353-8.

5. De Lancey JO. Anatomic aspects of vaginal eversion after hysterectomy. Am J Obstet Gynecol. 1992;166(6 Pt 1):1717-28.

6. Sederl J. Zur operation des prolapses der blind endigenden sheiden. Geburtshilfe Frauenheilkd. 1958;18:824-8.

7. Richter K, Albrich W. Long term results following fixation of the vagina on the sacrospinous ligament by the vaginal route (vaginaefixatio sacrospinalis vaginalis). Am J Obstet Gynecol. 1981;141(7):811-6.

8. Lantzsch T, Goepel C, Wolters M. Sacrospinous ligament fixation for vaginal vault prolapse. Arch Gynecol Obstet. 2001;265(1):21-5.

9. Persu C, Chapple CR, Cauni V, Gutue S. Pelvic Organ Prolapse Quantification System (POP-Q) - a new era in pelvic prolapse staging. J Med Life. 2011;4(1):75-81.

10. Olsen AL, Smith VJ, Bergstrom JO, Colling JC, Clark AL. Epidemiology of surgically managed pelvic organ prolapse and urinary incontinence. Obstet Gynecol. 1997;89 (4):501-6.

11. Randall CL,Nicols DH. Surgical treatment of vaginal inversion. Obstet Gynecol. 1971;38(3):327-32.

12. Beer M, Kuhn A. Surgical techniques for vault prolapse: a review of the literature. Eur J Obstet Gynecol Reprod Biol. 2005;119 (2):144-55.

13. Pollak J, Takacs P, Medina C. Complications of three sacrospinous ligament fixation techniques. Int $\mathbf{J}$ Gynecol Obstet. 2007;99(1):18-22.

14. British Society of Urogyneacology. Fact sheet: PostHysterectomy Vaginal Vault Prolapse Green-top Guideline No. 46 RCOG/BSUG Joint Guideline. July 2015. Available from: https://www.rcog.org.uk/globalassets/documents/gui delines/gtg-46.pdf.

15. Centre for Devices and Radiological Health. Fact sheet: Urogynecologic Surgical Mesh: Update on the Safety and Effectiveness of Transvaginal Placement for Pelvic Organ Prolapse, July, 2011. Available from: http://www.fda.gov/downloads/Medical Devices/ Safety/AlertsandNotices/UCM262760.pdf.

Cite this article as: Ramesh Kumar RK, Kamat L, Shilpa T, Andola S. Sacrospinous ligament fixation for prevention and treatment of vaginal vault prolapse: a retrospective study of 45 cases. Int J Reprod Contracept Obstet Gynecol 2016;5:4014-7. 